HISTORIAS DE NAVEGACIÓN Y ASTILLEROS:

un eje temático a activar en el litoral oriental del Río de la Plata y el bajo río Uruguay

Gustavo Olveyra

Arquitecto, Maestrando en Manejo Costero Integrado MCISur

Docente del Taller Apolo, Facultad de Arquitectura, Universidad de la República

Ana Perdomo

Licenciada en Oceanografía

Maestría en Manejo Costero Integrado MCISur, Universidad de la República

\title{
RESUMEN
}

Este trabajo propone implementar un parque patrimonial en Uruguay, en la región donde confluyen los ríos Uruguay y Paraná formando el Río de la Plata. El objetivo del parque es el desarrollo sostenible, a través de la puesta en valor de los recursos costeros en un amplio sector del territorio, en el marco de una estrategia de Manejo Costero Integrado. ${ }^{1}$

${ }^{1}$ Se entiende por Manejo Costero Integrado (MCl) el proceso multidisciplinar de integración de diversos niveles con interés en la costa para consensuar programas de protección y desarrollo sustentable de los ambientes costeros y sus recursos. El MCl asume la interdependencia de las comunidades humanas costeras y los recursos asociados, apela a la resolución de conflictos entre usuarios y la reducción de los impactos acumulativos, y considera la participación de las comunidades a escala local como un componente fundamental de la gestión. Internacionalmente, se considera al $\mathrm{MCl}$ como el enfoque más avanzado para integrar vertical y horizontalmente a técnicos, políticos y comunidades costeras, teniendo en cuenta la adaptación a escala local de la experiencia aprendida a escala internacional (http://www.mcisur.edu.uy/mci). 


\section{ID INVESTIGACIONES}

Como parte de esta idea, después de presentar los principales rasgos identitarios del área, selecciona uno de los múltiples ejes temáticos: el relato de la navegación y los astilleros en esta entrada estratégica al continente americano, como una línea de trabajo para poner en valor el paisaje y el patrimonio relacionado con los puertos y las vías navegables.

Palabras clave: patrimonio, astilleros, Río de la Plata, Uruguay

\section{ABSTRACT}

The purpose of this paper is the implementation of a heritage park in Uruguay at the region where rivers Uruguay and Parana converge, forming the Rio de la Plata. The aim of this park is to reach Sustainable Development through de activation of coastal resources, as part of a strategy of Integrated Coastal Management.

After presenting the main characteristics of the area, this work focuses on one of the multiple thematic threads: tales of dockyards and navigation at this strategic point of entry into the South American continent. A line of work to regain the landscape and heritage related to ports and navigation routes.

Key words: heritage, dockyards, Rio de la Plata, Uruguay

\section{INTRODUCCIÓN}

La activación del patrimonio natural y cultural desde una visión de Manejo Costero Integrado (en adelante $\mathrm{MCl}$ ) permite garantizar el desarrollo sostenible basado en los recursos costeros.

Situado en el Suroeste de Uruguay, en la margen izquierda del río Uruguay y el Río de la Plata, el ámbito geográfico abordado presenta características 


\section{ID I NVESTIG AC I O NES}

singulares por su ubicación y por su historia, que se proponen como elementos constitutivos de un parque patrimonial.

El parque articula una estrategia de $\mathrm{MCl}^{2}{ }^{2}$ Por medio de planes de acción estratégica se atiende cuatro asuntos clave: (1) Conservación y recuperación de áreas en ecosistemas sensibles y/o vulnerables; (2) Puertos y vías navegables; (3) Bienes culturales y patrimoniales, turismo y recreación; (4) Usos y actividades productivas en el ámbito terrestre. Estos cuatro "asuntos clave" del $\mathrm{MCl}$ tienen una expresión territorial variable, dependiendo de la escala en que se analicen. Para la delimitación de las áreas de acción, de influencia o "cuencas" (áreas de captación), se integran metodologías como el análisis de la topografía antropológica, lecturas sectoriales del territorio, y consideraciones de álgebra borrosa. De esa manera, se integran al análisis

\footnotetext{
${ }^{2}$ La propuesta se apoya en antecedentes realizados por los autores:

(1) El trabajo multidisciplinario Caso de Estudio Carmelo-Nueva Palmira (Perdomo et al., 2008) enfoca las múltiples dimensiones del territorio, y propone una estrategia de $\mathrm{MCl}$, articulada en base a planes de acción estratégica para los cuatro asuntos de manejo citados.

(2) Perdomo et al. (2009) consiste en un resumen de esta metodología presentado a la sociedad local, acompañado por un material de educación ambiental sobre los asuntos costeros, elaborado para la ocasión.

(3) Articulado en base a los asuntos de Manejo Costero Integrado, el trabajo de Olveyra e Ippoliti (2009) indaga en la factibilidad de creación de un Parque Natural Regional, como herramienta de planificación basada en la activación del patrimonio natural y cultural. La extensión del proyecto es variable y dinámica, buscando la integración sectorial de diversas actividades del medio terrestre y del medio acuático, en distintas escalas, a través de la adhesión progresiva de la sociedad civil del área.

(4) Perdomo y Olveyra (2009) analiza el Caso de Estudio Carmelo-Nueva Palmira mediante la metodología desarrollada por el Grupo de Investigación de Planificación y Gestión Integrada de Áreas Litorales de la Universidad de Cádiz, estructurando el análisis en los diez puntos del Esquema para el estudio de la planificación y gestión integradas de áreas litorales (PGIAL), y analizando los Asuntos clave para la Gestión ("Decálogo de la PGIAL") (Barragán, 2003). Los aportes de este documento son la verificación de los asuntos identificados y de las condiciones para la PGIAL, una profundización en la visualización de actores, sus roles, pesos relativos y competencias, y de los instrumentos jurídicos aplicables.
} 
aspectos culturales, como usos, preferencias, decisiones perceptuales, tradiciones y tendencias locales. El resultado es un planteo de límites dinámicos y flexibles, y una mirada holística y comprehensiva de la complejidad del territorio costero.

Este trabajo enfoca el asunto "Puertos y vías navegables", profundizando en el relato de un sector de actividades: las construcciones navales y la navegación. A través de su implementación, se propone gestionar los recursos de esta área costera, desarrollando grados crecientes de adhesión y participación, generando nuevos atractivos turísticos e incentivos para la producción sustentable.

\section{PRESENTACIÓN DEL ÁREA}

Al sur de la banda oriental del río Uruguay, en su desembocadura en el Río de la Plata, se encuentra la región oeste del Departamento de Colonia, Uruguay. Los principales centros poblados en el área son las ciudades de Carmelo y Nueva Palmira. Con 16.900 y 9.200 habitantes respectivamente, estos centros urbanos están ubicados en un área rural que presenta una población dispersa de unos 2.300 habitantes, y en el contexto cercano una población de 8.500 habitantes, distribuidos en centros poblados más pequeños, como Balneario Zagarzazú, Balneario Punta Gorda o Conchillas, y enclaves en parajes rurales como Costas de Juan González, Martín Chico, y Cerros de San Juan, entre otros. Esta distribución demográfica es relativamente equilibrada en el espacio, característica del Departamento, y diferente del patrón uruguayo que por regla general presenta población concentrada en escasos centros poblados.

El área núcleo objeto de este trabajo se extiende a lo largo de aproximadamente $85 \mathrm{~km}$ de costa, y tiene un área de influencia de dimensión variable hacia el ámbito terrestre, cubriendo unos $500 \mathrm{~km}^{2}$ (50.000 ha). La

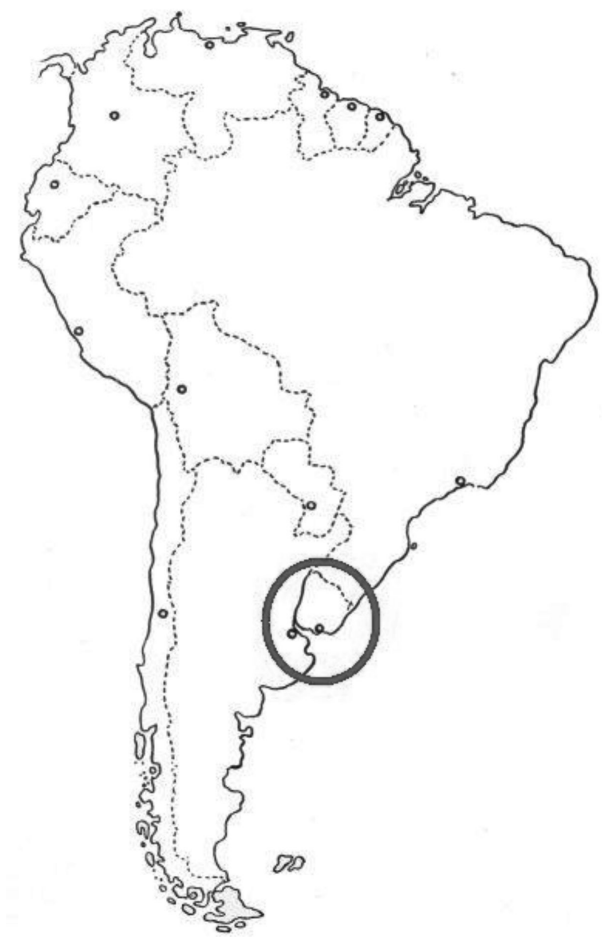

El área en el contexto continental 
dimensión acuática del área tiene un amplio horizonte con proyecciones transfronterizas de agua, vegetación, cemento y embarcaciones, aún cuando existen límites jurisdiccionales definidos para el despliegue de acciones. ${ }^{3}$

Las características históricas más notables de este territorio están relacionadas con su ubicación estratégica, en el punto de entrada de los navegantes españoles a la región (siglo XVI en adelante). La primera expedición española arribó al Río de la Plata en 1516, al mando de Juan Díaz de Solís, quien según las crónicas encontró la muerte en el paraje llamado Punta Gorda. Allí se erige un obelisco conmemorativo, y el enorme cuerpo de agua se denominó por largo tiempo "río de Solís". Sin embargo, la Corona española comenzó tardíamente la colonización de estas tierras por considerarlas "tierras de ningún provecho", en la etapa en que se priorizaba la extracción de piedras y metales preciosos en otras regiones de América. Con intereses geopolíticos, la Corona portuguesa estableció su primer enclave en 1680 con la fundación de la Colonia del Sacramento frente a Buenos Aires, plaza militar que sería objeto de disputa entre ambos imperios durante largos años. El primer enclave militar de las autoridades españolas se fundó recién en 1724 en la Bahía de Montevideo, único puerto natural de importancia en el Río de la Plata, que más adelante cumpliría el rol de apostadero naval para el Atlántico Sur. Próximo al área de estudio, Hernandarias introdujo los primeros ejemplares de ganado vacuno en 1611, y se comenzaron a establecer las primeras estancias jesuíticas y los primeros pueblos misioneros orientales (Guía del Mundo, 2008).

En adelante, la historia local tiene gran riqueza de acontecimientos épicos: españoles y criollos, ingleses, franceses, unitarios, federales, portugueses y el Imperio del Brasil lucharon por el control del río Uruguay. Por aquí pasaron
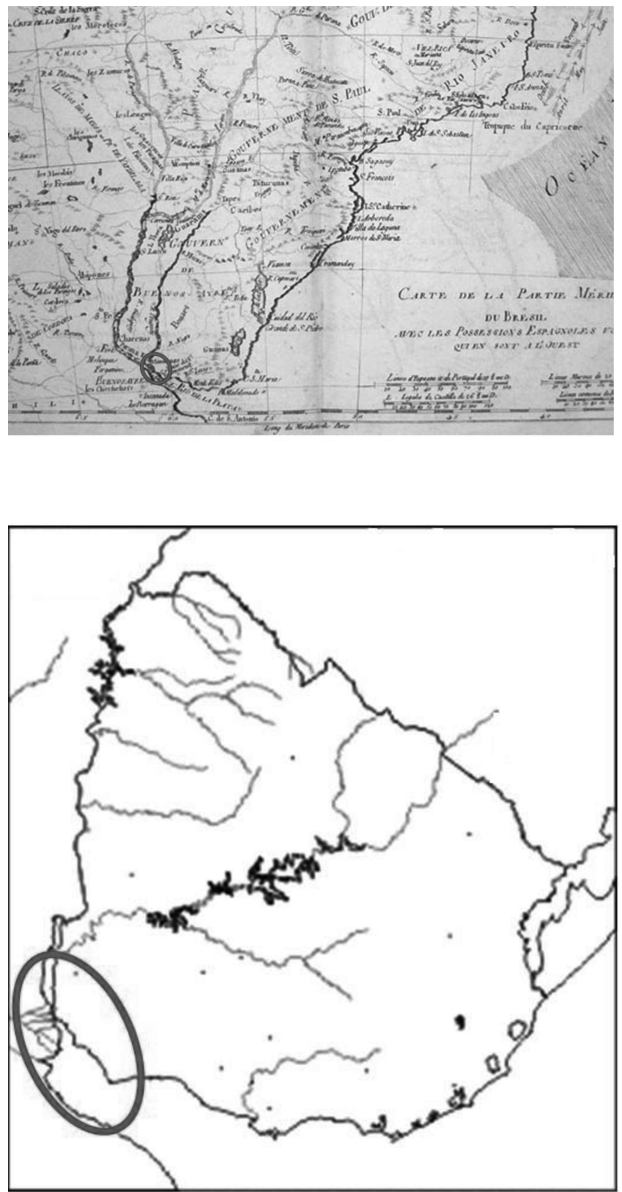

El área en el contexto regional y nacional

${ }^{3}$ El Tratado del Río Uruguay y el Tratado del Río de la Plata son los instrumentos jurídicos bilaterales vigentes entre Argentina y Uruguay para regular el uso de ambos cuerpos de agua 


\section{ID_INVESTIGACIONES}

corsarios de la independencia, sucedieron batallas contra la dominación portuguesa en el arroyo de Las Vacas, y el "Desembarco de los Treinta y Tres Orientales" "4 que dio inicio a la gesta emancipadora contra el Brasil, que condujo al proceso de creación del estado nacional actual.

Se produjo también la presencia de Charles Darwin en su viaje a bordo del Beagle, observando atentamente las barrancas sedimentarias de la costa oriental, deteniéndose en estos parajes y admirando el paisaje, en 1833. El río Uruguay, visto desde ese punto, ${ }^{5}$ presenta una magnífica masa de agua. Lo claro y lo rápido de la corriente hacen que el aspecto de este río sea muy superior al de su vecino, Paraná. En la margen opuesta, varios brazos de este último río desaguan en el Uruguay. Brillaba el sol y podía distinguirse con claridad el diferente color de las aguas de ambos ríos (Darwin, en Blasina, 2009).

Además de la ganadería de carácter pionero que dio origen a construcciones del siglo $\mathrm{XVIII}^{6}$ como la Estancia y Capilla Narbona o el establecimiento jesuítico Estancia de las Vacas-Calera de las Huérfanas, se asentaron en esta área los primeros emprendimientos industriales: molinos, viñedos y bodegas, e industrias extractivas de arena, piedra y cal, que abastecían a la ciudad de Buenos Aires.

Avanzado el proceso de construcción de la nación, el país recibe contingentes migratorios europeos de diverso origen: vascos, mallorquines, italianos, suizos,

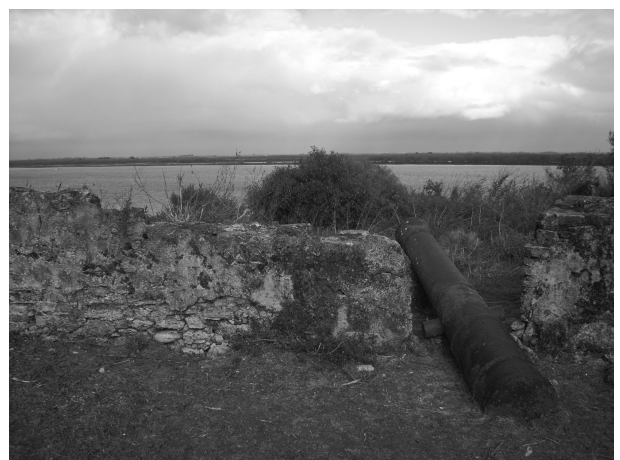

La confluencia del río Uruguay y el río Paraná en Punta Gorda, km Cero del Río de la Plata

\footnotetext{
${ }^{4}$ El Desembarco de los Treinta y Tres Orientales, provenientes de la margen derecha del río Uruguay, se produjo en 1825, a escasos kilómetros río arriba, en la Playa de La Agraciada (actual Departamento de Soriano). Este hecho se considera el inicio de la Cruzada Libertadora contra el Imperio del Brasil, que dominó el país poco después de la derrota española por parte de las fuerzas orientales.

${ }^{5}$ Esta visita está señalada con un hito en el llamado "Rincón de Darwin" de Punta Gorda, paraje ubicado entre Nueva Palmira y Carmelo, donde también se encuentra la Pirámide de Solís, y el hito que señala el entre Nueva Pal sío de Calo (Kilóme tambièn se

${ }^{6}$ La Estancia Narbona y la Calera de las Huérfanas han sido declaradas Monumento Histórico Nacional y están siendo objeto de proyectos de recuperación y puesta en valor.
} 


\section{ID_INVESTIGACIONES}

rusos y alemanes, entre otros, muchos de los cuales se asientan en la región estudiada.

Como testimonio de estos hechos, hay en el área numerosos hitos conmemorativos, y testimonios cuya distribución hemos georreferenciado en la ¡Error! No se encuentra el origen de la referencia.: El molino Camacho, el puente Castells, construido en piedra sobre el arroyo Las Víboras y que aún está en servicio; vestigios de estructuras militares como la batería del General Fructuoso Rivera en Punta Gorda, que custodiaba la entrada al río Uruguay; los centros poblados de Conchillas y El Cerro, surgidos en torno a industrias extractivas; la bodega Los Cerros de San Juan, con ingeniosos sistemas de frío en base a elementos naturales; frontones de pelota vasca; embarcaderos y muelles originados por la exportación de arena, piedra y cal; canteras activas o abandonadas; modestos edificios religiosos, antiguos cascos de estancia, y la propia toponimia.

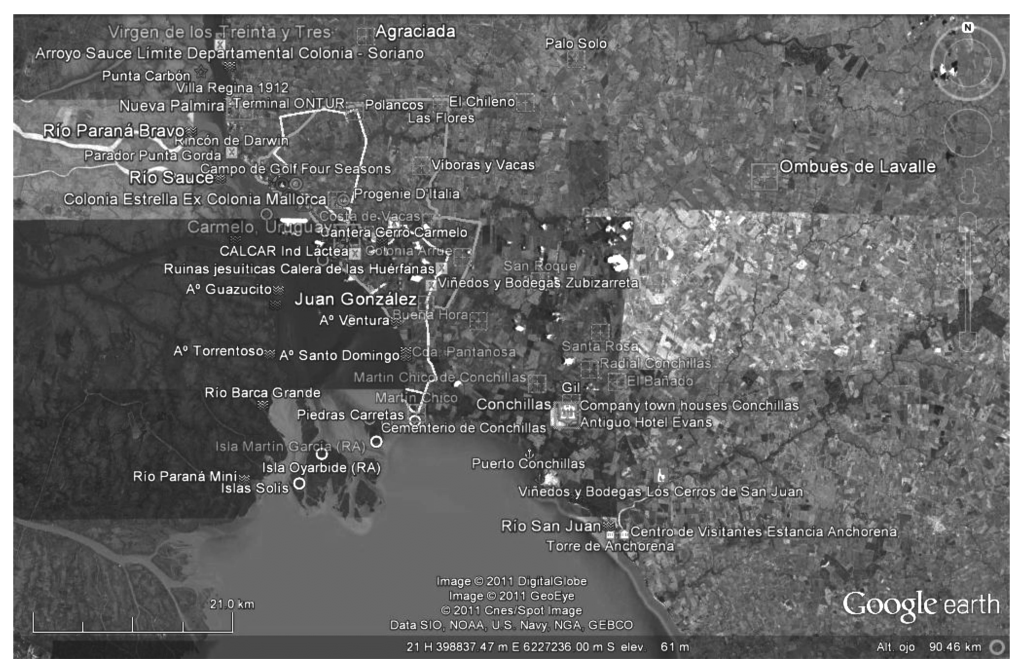

Imagen satelital del área, donde puede apreciarse la densidad de puntos notables 


\section{EL COMPONENTE SOCIAL Y CULTURAL}

A tres horas por tierra de Montevideo -capital del país que concentra la mitad de población uruguaya- el área se encuentra a escasa distancia del área metropolitana de Buenos Aires, que con sus 13 millones de habitantes (Pereyra, 2004) es la tercera aglomeración de América Latina, después de las ciudades de México y San Pablo (Reboratti, 2010). Buenos Aires utiliza los espacios a su alrededor para fines productivos y recreativos con una lógica transfronteriza, extendiendo su potencial económico, cultural y de movilidad a la serena "otredad" allende el río, disfrutando de su naturaleza y su gente. Esta presencia se percibe a través los medios de comunicación masiva, en la dinámica impresa por emprendedores argentinos en las actividades agropecuarias locales, en la existencia de importantes clubes de campo y emprendimientos turísticos costeros de una escala que responde a otros mercados, en la visita permanente de embarcaciones deportivas, y en el acento de los comensales en los bares locales. La población local acepta esta realidad cultural y económica como una oportunidad que constituye en ocasiones un fuerte factor de dinamismo. Esta relación confiere cosmopolitismo a la cultura local, que sin embargo mantiene rasgos de identidad y un sentimiento de propiedad de su historia, de su cultura y su territorio. La diversidad del tejido social local se expresa en fiestas locales, usos y costumbres, la gastronomía y los productos artesanales y en el recuerdo de las generaciones pasadas.

Este estilo de vida resulta sumamente atractivo para el visitante. El área cuenta con playas de río de finas arenas doradas que en verano son el espacio de recreación y disfrute de los habitantes. Pero no es ésta un área donde predomina la propuesta turística de sol y playa. El visitante recorre el campo, los sitios patrimoniales, navega sus ríos y arroyos, realiza actividades al aire libre, turismo de naturaleza y turismo cultural.

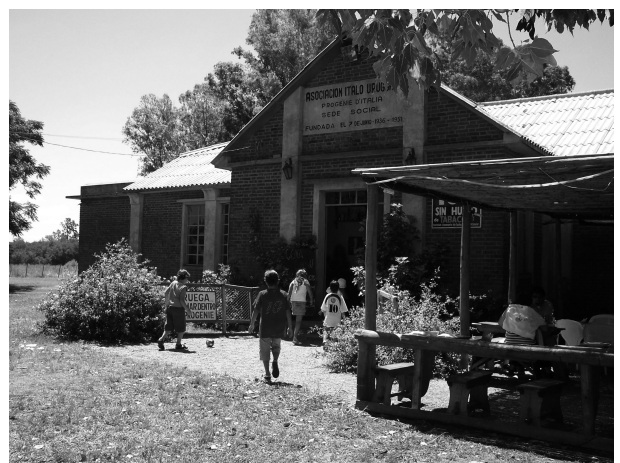

Asociación Ítalo Uruguaya, donde la población local y la "farándula porteña", degustan el plato único:"ravioli" caseros y vinos "del país"

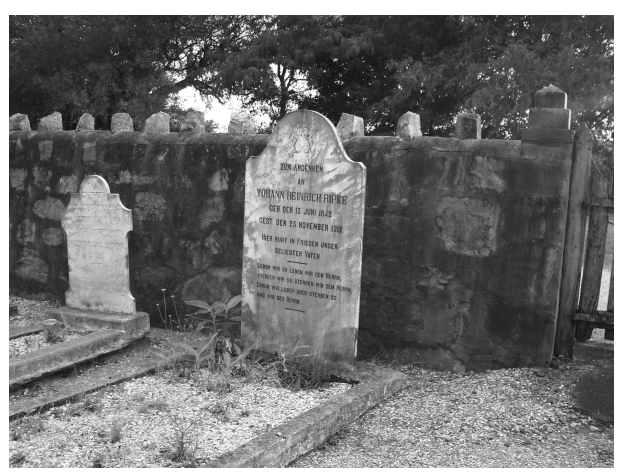

Antiguo cementerio de Conchillas, donde las lápidas en inglés y en alemán testimonian la diversidad de la herencia cultural 


\section{CONDICIONES PARA LA NAVEGACIÓN}

Una serie de condiciones permitieron el desarrollo temprano de la navegación y de industrias navales en el área.

\subsection{La ubicación estratégica}

En la confluencia de los ríos Uruguay y Paraná en su desembocadura en el Río de la Plata, esta posición geográfica es el acceso a la Hidrovía UruguayParaná-Paraguay, lo que hace del Sistema Portuario de Nueva Palmira un puerto estratégico a nivel continental.

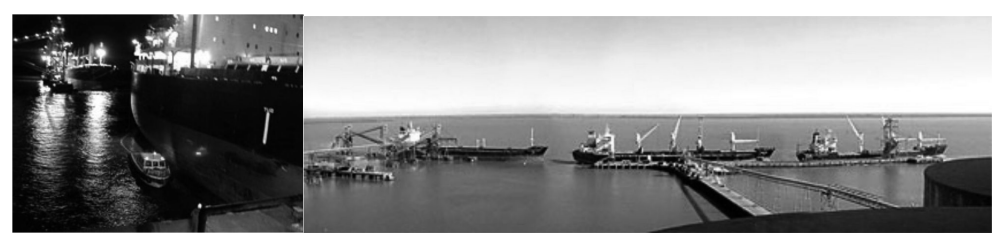

Sistema portuario de Nueva Palmira, puerto terminal de la Hidrovía. Visión nocturna y panorámica. Fuente: ANP, 2010

A su vez, desde el punto de vista turístico y cultural, esta ubicación y su calidad de espacio limítrofe le confieren particularidades culturales y atractivos. Está situada a unas escasas 35 millas náuticas del Área Metropolitana de Buenos Aires, lo que origina un tránsito de pasajeros cotidiano y fluido (llustraciones 8 y 9), y la presencia permanente de navegantes argentinos. A su vez, la ciudad de Colonia del Sacramento, declarada por la UNESCO Patrimonio Cultural de la Humanidad se encuentra a unos $60 \mathrm{~km}$, una distancia razonable para visitas por el día.

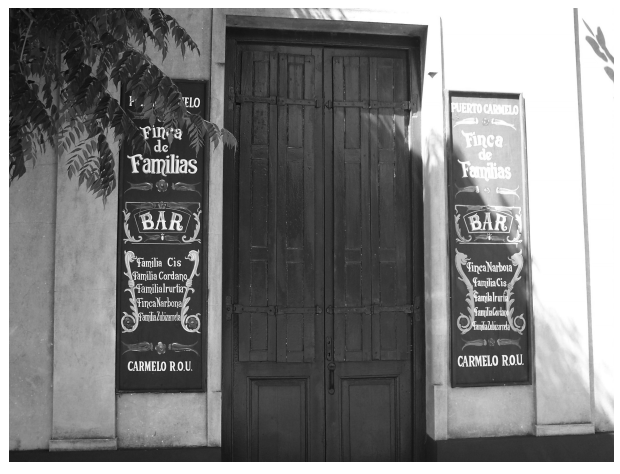

Bar en Carmelo: degustación de vinos de la zona. En algunos casos cuentan con Denominación de Origen Carmelo.

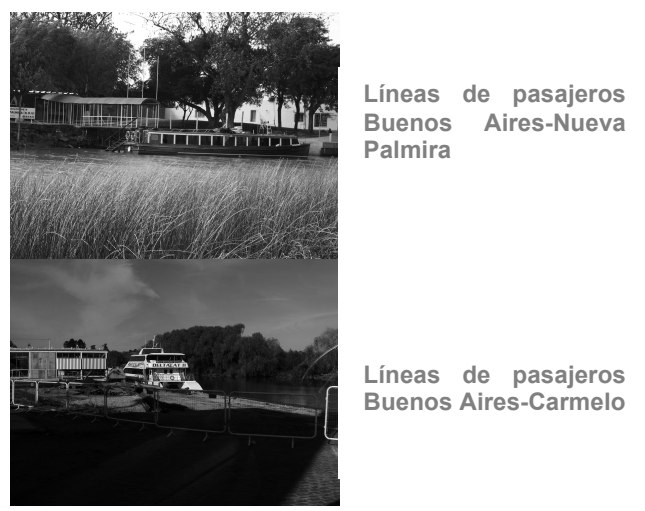




\subsection{El componente físico natural}

La costa presenta arcos de playas arenosas apoyados en puntas rocosas, y sectores de barrancas sedimentarias de altura considerable con importantes yacimientos fósiles. El transporte litoral de sedimentos se produce en dirección río arriba, por los vientos dominantes. La costa presenta dinámicas similares a las del mar, con mareas y oleaje (Soriano, 1995).

La costa oriental, a diferencia de la costa de Buenos Aires, cuenta con yacimientos de caliza y reservas de arena, que se encuentran también varios kilómetros tierra adentro. Estas acumulaciones son producto de las sucesivas transgresiones del Río de la Plata durante su evolución geológica. En efecto, en algunos momentos de la historia la costa se encontraba muchos kilómetros mar adentro de su ubicación actual; en otros momentos, el territorio que hoy conocemos fue parte del fondo marino durante largos períodos. En estas formaciones del paleocauce se da una importante presencia de fósiles.

La vegetación autóctona de juncales y monte costero se mezcla con especies introducidas. En los arenales y médanos secundarios se generan importantes corredores biológicos que resuelven la transición con la pradera natural, suavemente ondulada, y con cultivos agrícolas. En estos ambientes se presentan variadas especies de fauna autóctona, en especial de aves, que incluso encuentran significancia en la toponimia. Según la versión poética de Juan Zorrilla de San Martín, Uruguay significa "Río de los Pájaros Pintados", en lengua indígena. El medio acuático es hábitat de variadas especies, destacándose el sábalo como principal especie comercial de la pesca artesanal.

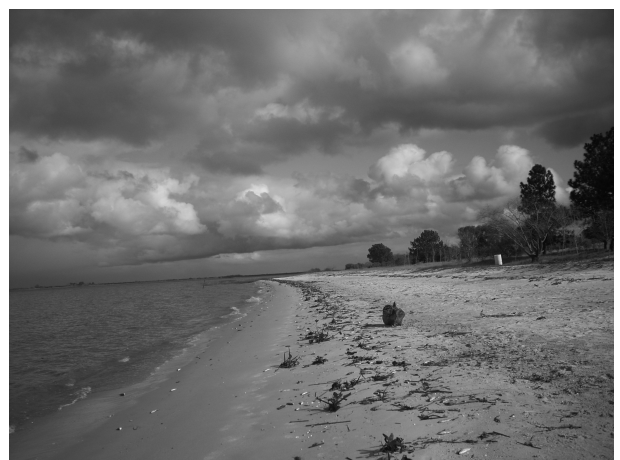

Vista río arriba. Playa en Balneario Zagarzazú, al Norte de Carmelo

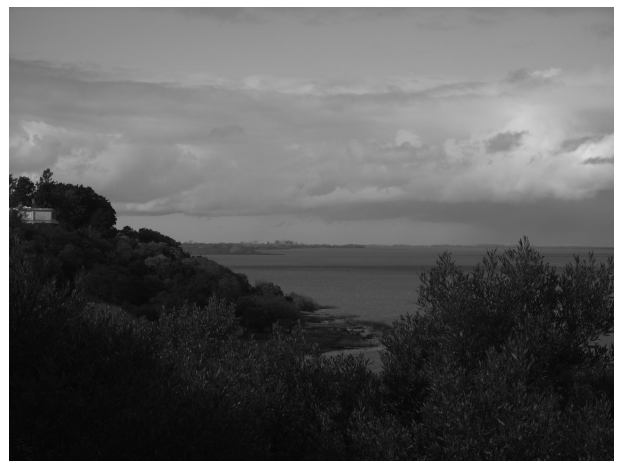

Vista río abajo, puntas rocosas y arcos de playa desde Punta gorda, al Sur de Nueva Palmira 


\subsection{La navegabilidad}

El área presenta condiciones naturales excepcionales para la navegación. La cuenca del Río de la Plata es una de las más importantes del mundo, con 3.170.000 km2 (Tossini, 1959; en López Laborde, 1997). Sus tributarios principales, son el río Uruguay (con un caudal medio de $5.000 \mathrm{~m} 3 / \mathrm{s}$ ) y el río Paraná ( $17.000 \mathrm{~m} 3 / \mathrm{s})$, que confluyen en el área de estudio en el llamado "Paralelo Punta Gorda", formando el Río de la Plata.

El río Paraná transporta 160 millones de toneladas anuales de sedimentos, que provocan un avance anual de varias decenas de metros en el frente del delta de su desembocadura (Sarubbi et al., 2005). El río Uruguay, en cambio, corre sobre un lecho cristalino, transportando sedimentos de granulometrías correspondientes a arenas y cantos rodados predominantemente.

Si bien el Río de la Plata interior ${ }^{7}$ presenta una profundidad media de $5 \mathrm{~m}$, existen condiciones para la navegación de gran calado. En efecto, las características paleogeográficas del área de estudio sumadas a las forzantes hidrológicas y la geología de la costa y del fondo del Río de la Plata y del río Uruguay, dan lugar a canales naturales navegables ubicados contra la margen uruguaya de estos cuerpos de agua.

En la actualidad, mediante dragado estos canales permiten el tránsito de buques transoceánicos hasta Nueva Palmira, y por diferentes brazos del delta, hasta Rosario y los puertos argentinos del río Paraná.

Estas condiciones naturales han dado origen al desarrollo portuario nacional y regional. El transporte acuático desplaza la mayor parte de los bienes intercambiados por el Uruguay con el exterior, y la tendencia es creciente. En

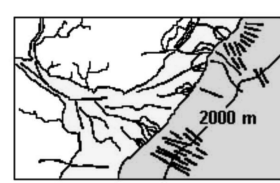

Previo a los 14.000 a. A.P.

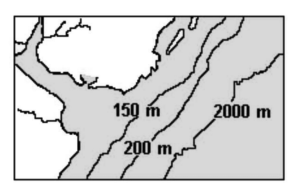

6.000 a 4.000 a.A.P.

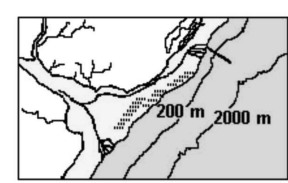

11.000 a 6.000 a.A.P.

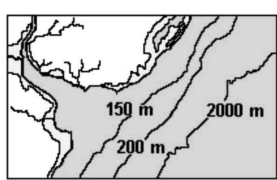

4.000 a.A.P. al Presente
Planicie
costera Paleocauces $\quad .: .:{ }_{\text {Barrera }}^{\text {Isla }}$

Evolución del Río de la Plata. Fuente: Cayssials et al. , 1999

\footnotetext{
${ }^{7}$ Tramo del río de la Plata comprendido entre Punta Gorda y Colonia del Sacramento, con anchos de 2 y $50 \mathrm{~km}$, respectivamente.
} 


\section{ID I N VESTIGACIONES}

este contexto, Nueva Palmira se ha desarrollado como puerto granelero, y es en la actualidad el segundo del país en volumen de mercancía, contando con áreas al servicio del comercio de países como Paraguay y Bolivia, que no cuentan con una salida directa al mar.

El arroyo de las Vacas, si bien ha tenido mayor uso como vía y puerto comercial en otros momentos, por sus condiciones naturales, en la actualidad tiene un uso predominante dado por instalaciones náuticas, embarcaciones deportivas y líneas fluviales de pasajeros. Aguas arriba de Carmelo, se situaba la cantera Cerro Carmelo, proveedora de obras de infraestructura como el puerto de Mar del Plata y Puerto Madero, en Buenos Aires (Bacigalupe, comentario personal 2010). El arroyo ha sido utilizado por varias industrias navales en distintas épocas. Allí se construyeron y repararon embarcaciones para la navegación en los ríos de la Cuenca del Plata. En la actualidad, esta actividad se mantiene, aún cuando la globalización y el desarrollo de los astilleros argentinos dominan el mercado.

\section{UNA HISTORIA PARA CONTAR}

Las condiciones naturales y estratégicas, y los procesos antes descritos dan estructura a una historia multitemática que el área tiene para contar. Con la introducción del ganado vacuno por Hernandarias en 1611, la "Vaquería del Mar" se convirtió en una suerte de coto de caza de ganado silvestre para navegantes, nativos y piratas. Desde entonces, se ha desarrollado hasta su realidad actual de ganadería de exportación, con énfasis en la excelencia y en la alimentación natural del ganado. Viñedos, bodegas, lechería y tradiciones rurales, de gran vitalidad y vigencia, también forman parte del relato del área, con actividades de tipo familiar artesanal -son reconocidos sus productos como el queso "Colonia" y los vinos locales-, a industrias lácteas, frigoríficos y bodegas de proyección internacional. La exportación de arena, cal y piedra

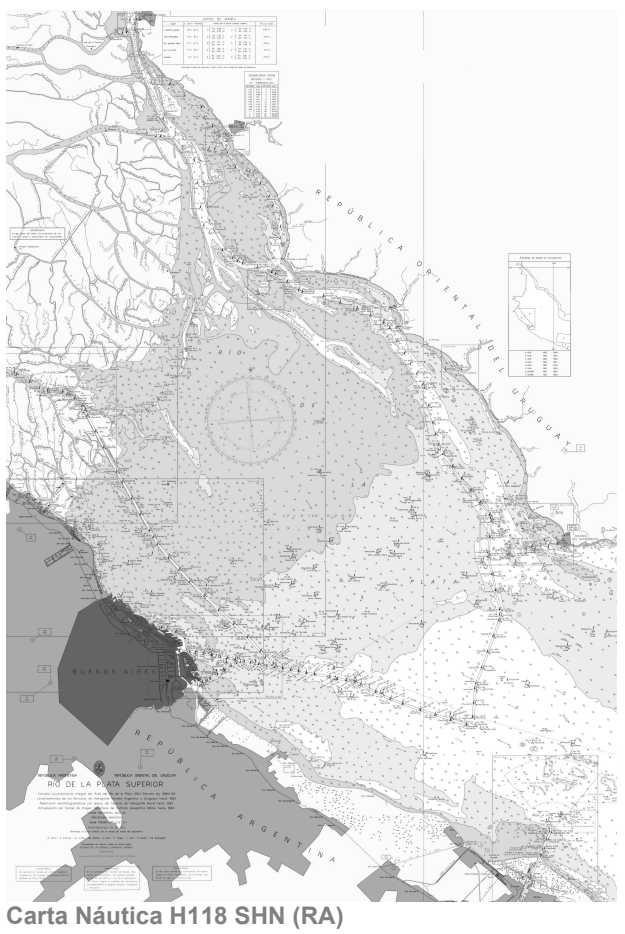

Carta Náutica H118 SHN (RA) 
ID_INVESTIGACIONES

Dio lugar tempranamente a establecimientos, "company towns" e infraestructuras costeras.

El paisaje cultural y el patrimonio construido dan testimonio de esta evolución.
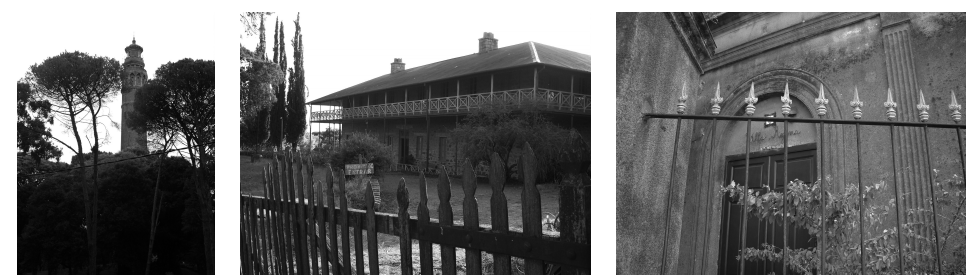

Torre en Parque Anchorena - Villa Regina, Nueva Palmira - Hotel Evans, 1912, Conchillas

Nuestro relato se apoya en la huella tangible de las actividades humanas, que han modelado paisajes culturales de alto valor, y han tenido su expresión tanto en el ámbito terrestre como en el acuático y costero. Pero también se respira en la diversidad cultural local, donde los apellidos, las facciones, las tradiciones y oficios, y los productos de la tierra, dan cuenta de un pasado que invita a conocerlo.

Los bienes patrimoniales, testimoniales y culturales poseen, antes que nada, un valor simbólico e identitario. Para que puedan convertirse en patrimonio es preciso poner en marcha una serie de estrategias, un proceso de "patrimonialización" en el que participe la sociedad. Es muy importante conservar el patrimonio, ya que es un referente simbólico de los valores de identidad, por lo que su conservación debería jugar un rol importante en las decisiones de los organismos competentes para su conservación (Méndez, 2002). Este proceso, que Prats (1997) llama activación del patrimonio, comporta una selección local de los elementos a patrimonializar (Kravets y Camargo, 2008).

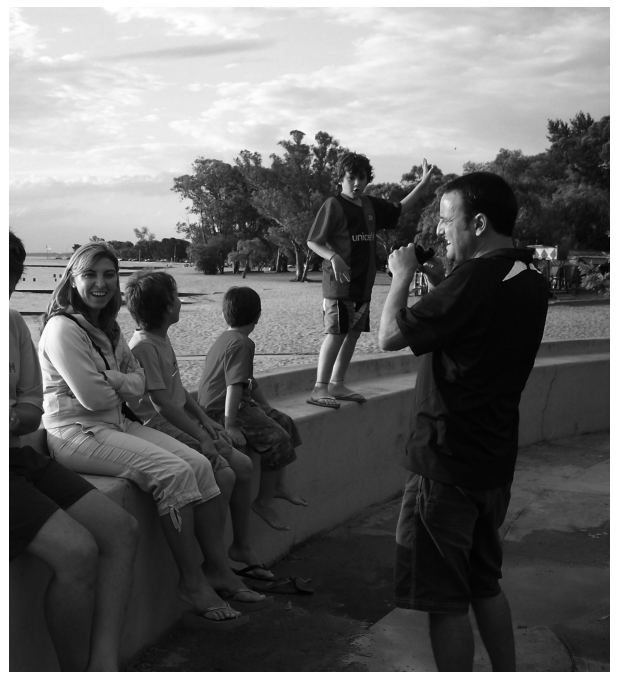

Visitantes y pobladores locales en Paseo Costero en Playa Seré, Carmelo 
Entre los múltiples ejes del relato, existe uno que por su singularidad amerita una puesta en valor específica, ya que constituye un rasgo diferenciador y característico del área: Historias de navegación y astilleros.

\subsection{La navegación y la construcción naval: actividades con raíces históricas fundacionales}

Dado el escaso desarrollo de la vialidad y de los medios de transporte terrestre en el siglo XIX y primera mitad del XX, la navegación fluvial tuvo un rol primordial, sirviendo a centros poblados de ambas márgenes del río Uruguay, entregando mercancías y correo, y transportando pasajeros.

En 1844 se crea la Receptoría General del río Uruguay en Higueritas, y el resguardo del puerto de Las Vacas. Las ventajas de calado y abrigo de este último explican que en pocos años ya se realizaba navegación regular de cabotaje desde allí a Montevideo y Buenos Aires. En la segunda mitad del siglo XIX se crea la Sociedad Navegación a Vapor de Carmelo, y en el último cuarto del siglo se realizan tareas de canalización del arroyo. Estas obras y una Receptoría en el Puerto se inauguran a fines del siglo.

En 1905 Don Nicolás Mihanovich instaló su astillero en la costa del arroyo Las Vacas junto a la ciudad de Carmelo. Allí se instaló la Comisión de Estudios Hidrométricos del Río de la Plata. En los primeros años del siglo XX la intensidad de la navegación motiva trabajos de dragado, mientras que emprendedores privados comienzan a construir muelles e infraestructuras para las industrias extractivas que exportaban materiales de construcción y productos agrícolas.

La importancia de la navegación en el arroyo de Las Vacas motivó que la construcción de un puente sobre el mismo para el arribo a Carmelo desde Colonia del Sacramento requiriera resolver el paso de embarcaciones de porte,

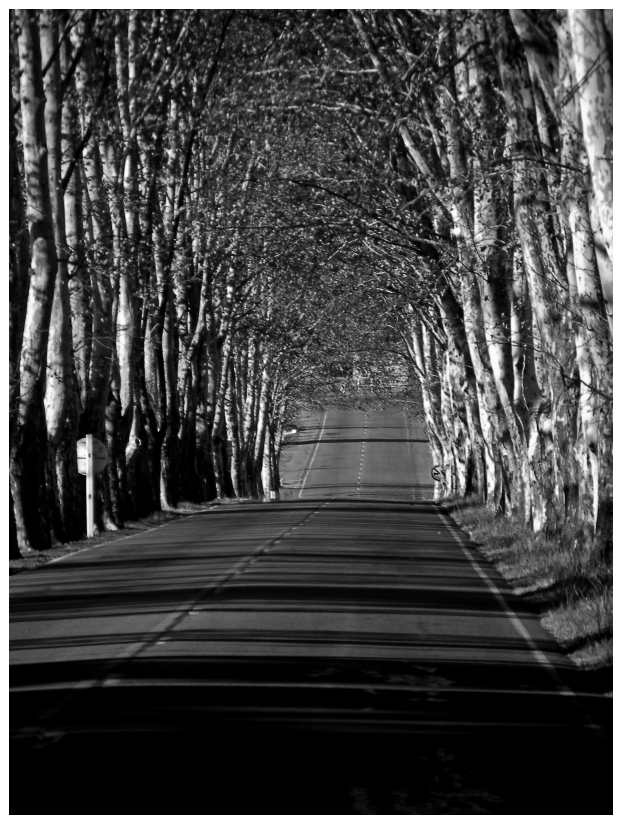

Bóvedas de plátanos en los accesos a Carmelo 
aguas arriba del mismo. Por este motivo, se opta por construir un puente giratorio, un tipo de infraestructura novedoso en el continente, cuya estructura metálica se encargó a Europa. El puente giratorio de Carmelo funciona con tracción humana, y la comunidad ha colocado en su arco la leyenda de que quien lo cruza, vuelve a Carmelo.

Según Parodi (2010), en 1925 la ciudad contaba con unos diez mil habitantes, y por entonces comienza la construcción del atracadero de yates. En los años siguientes se funda el Carmelo Rowing Club, institución de gran vitalidad hasta nuestros días, y se comienza la construcción de la Playa Seré, hoy convertida en un hermoso parque y playa muy utilizada por la comunidad local.

1930 es el año del Centenario de la primera Constitución uruguaya. Son años de intenso optimismo: Uruguay es sede del primer Campeonato Mundial de Fútbol, y las obras públicas tienen una envergadura admirable, y una formalización arquitectónica racionalista de vanguardia. De acuerdo a información de Parodi, es en ese año que en Carmelo, el arroyo de Las Vacas, eje de las actividades náuticas, es dotado de una rambla costanera con espacios públicos cuidadosamente diseñados. Los viajes de conexión fluvial con la ciudad bonaerense de Tigre comienzan a realizarse de forma regular en lanchas de pasajeros, algunos años antes de que se establecieran líneas regulares de omnibuses a Montevideo. Sobre fines de esta década se instala el Varadero de la Dirección Nacional de Hidrografía, un surgidero y taller de construcciones y reparaciones navales aún activo en la actualidad.

En la década de 1920, un ingeniero francés inicia un establecimiento elemental de reparaciones navales, en un predio sobre el arroyo que luego ocupó la empresa "Constructora Naval Uruguaya Limitada" (CNUL). Allí se instaló en 1944 el Astillero Carmelo de la Empresa Metalúrgica y Diques Flotantes S.A. (MDF), que empleó numerosa mano de obra local, y tuvo excelentes especialistas extranjeros de diverso origen. Sus instalaciones permitían la

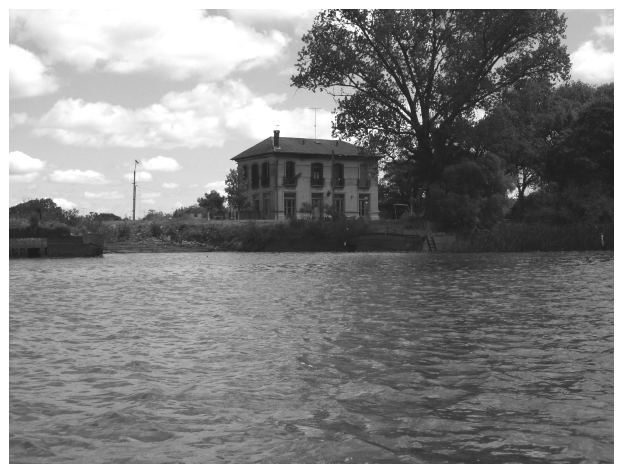

Antiguas construcciones del astillero Mihanovich, hoy vivienda particular.

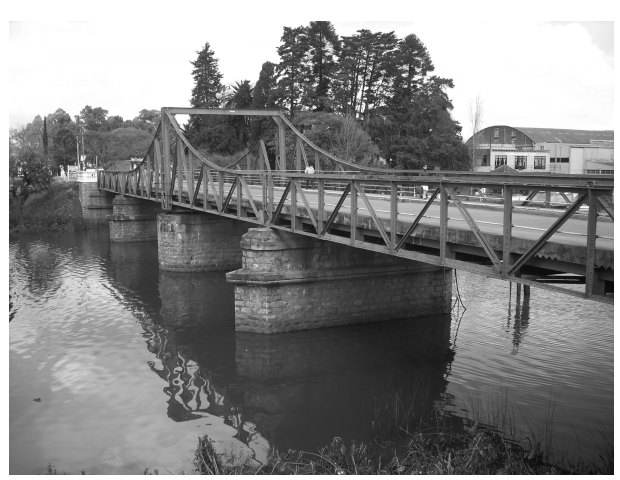

Puente giratorio sobre arroyo de las Vacas, Carmelo 
construcción simultánea de numerosos buques. Las características y la ubicación estratégica de la escala del surgidero, dispuesta en un meandro en forma oblicua a la costa del arroyo, permitían salvar el impedimento del ancho del cauce para trabajar con embarcaciones de grandes dimensiones; siendo el calado en el arroyo de 4,5 metros, la limitante a atender es la luz libre entre pilares del puente giratorio. Todas las secciones tenían instalaciones $y$ maquinarias de última generación para la época, proveniente en su mayoría de EE.UU. que aún se conservan y se utilizan en la actual Escuela de Reparaciones Construcciones Navales y Anexos, dependiente del Consejo Educación Técnico Profesional (Bacigalupe, 2009).

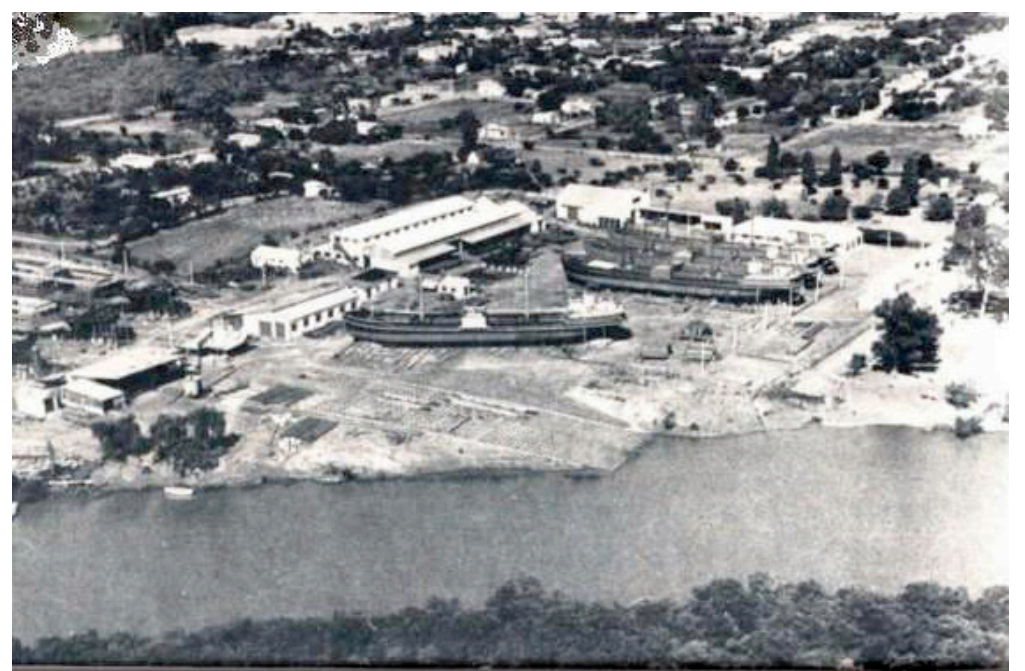

Vista aérea del Astillero Carmelo de MDF, hoy Escuela Técnica. Fuente: Bacigalupe, 2009

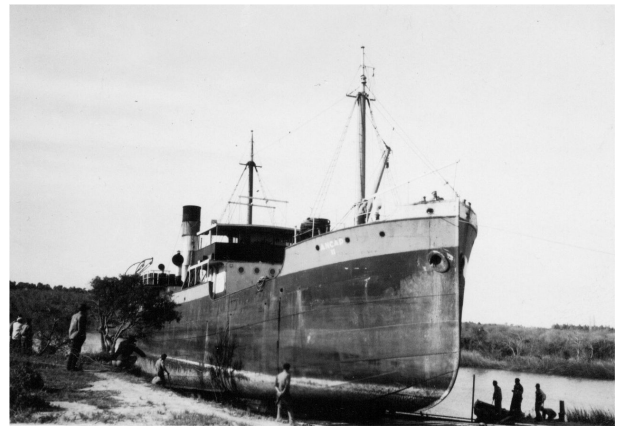

CNUL, ANCAPII, 1944 Fuente: Bacigalupe, 2009

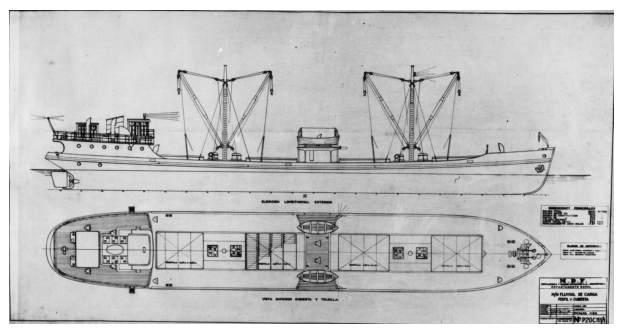

En el Astillero Carmelo se construyeron los P20C, de $60,82 \mathrm{~m}$ de eslora, 9,50 de manga, un calado máximo de $2,75 \mathrm{~m}$. Su volumen de bodegas era de $1.203 \mathrm{~m}^{3}$, y el Desplazamiento de agua dulce era de 1.107 Ton. Propulsión:IMT 400HP-6 cilindros Diesel

Fuente: Bacigalupe, 2009 
ID_INVESTIGACIONES

Esta empresa, si bien tuvo una corta duración por los avatares del mercado y los vaivenes de su administración, marcó la vida de las familias carmelitanas (Bacigalupe, 2009).

Las actividades de construcción y reparaciones navales se desarrollaron en Carmelo durante largos años, generando mano de obra local cualificada, infraestructuras y un posicionamiento interesante de los astilleros del arroyo de Las Vacas. En la actualidad, los cambios en las técnicas de construcción de barcos, la fabricación a gran escala de embarcaciones recreativas en Argentina, el auge del transporte carretero de cargas, fenómenos de competitividad y los cambios de escala de la navegación fluvial de pasajeros y de cargas, son razones que podrían explicar lo reducido de estas actividades. Hoy el antiguo astillero Mihanovich se encuentra inactivo, junto al muelle del puerto de las Vacas. Río arriba, existen dos astilleros privados con diferente grado de actividad.

El Varadero de la Dirección Nacional de Hidrografía está en actividad, realizando construcciones navales públicas, y mantenimiento de embarcaciones y dragas del Ministerio de Transporte y Obras Públicas.

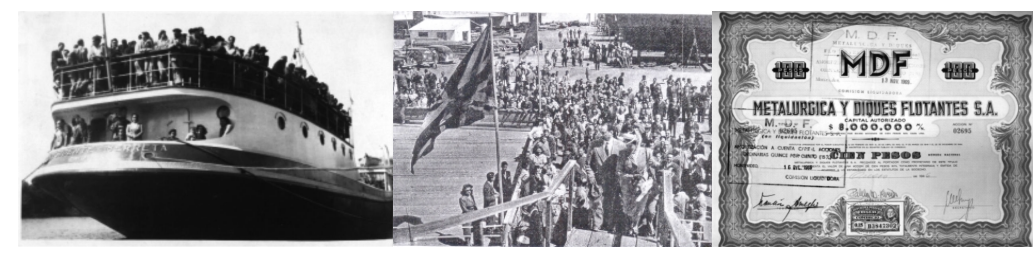

Botadura del "Presidente Berreeta", con la presencia de la población de Carmelo, el Presidente Luis Batlle Berres y su esposa, Matilde Ibáñez, madrina de la embarcación, 1947- Acciones de la compañía MDF, propietaria del Astillero Carmelo.

Fuente: Bacigalupe, 2009
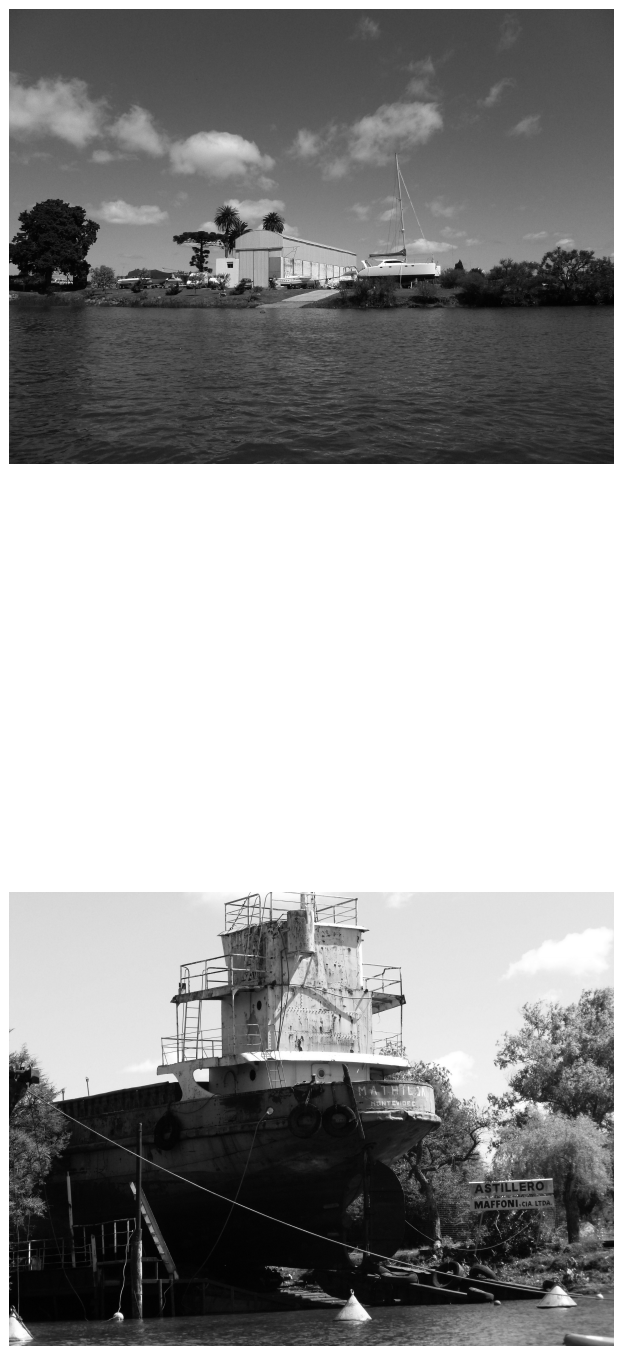

Astilleros privados en el arroyo de las Vacas, 2010 


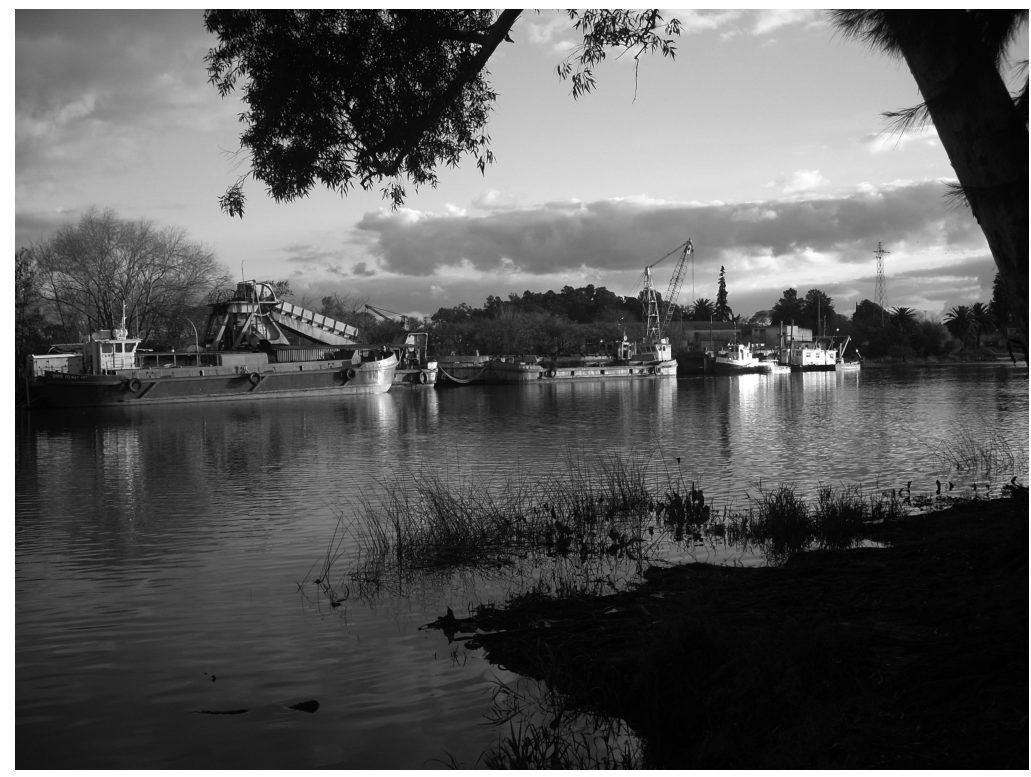

Varadero de DNH, 2010

La Universidad del trabajo del Uruguay tiene en 2010 unos 130 jóvenes en la Escuela de Reparaciones y Construcciones Navales, fundada en 1967 en las ex instalaciones del Astillero Carmelo de MDF (Merillo, comentario personal 2010). Si bien el Varadero estuvo sin actividad unos diez años, en la actualidad se está trabajando con el objetivo de realizar el aprendizaje trabajando sobre embarcaciones reales. Con esta estrategia, en la década de 1980 se reparaban una veintena de embarcaciones al año. Su sala de gálibos, única por sus características, se mantiene intacta en la actualidad. Los operarios caminaban con medias blancas sobre los dibujos realizados en el piso, para plantillar las piezas de las embarcaciones.

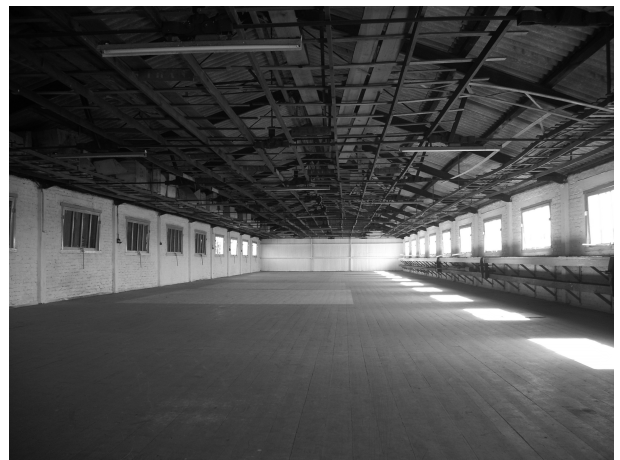

Sala de Gálibos del antiguo astillero Carmelo de MDF

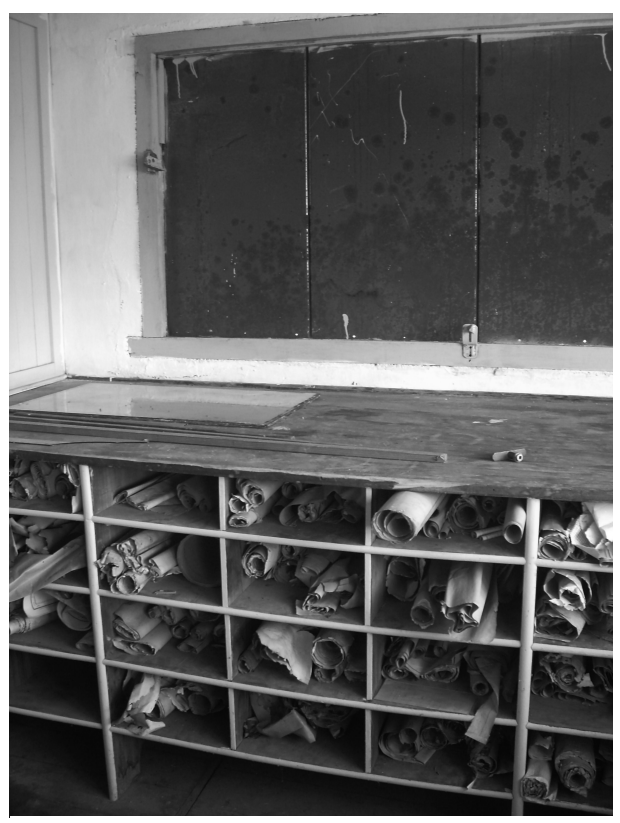

Planos de embarcaciones en Sala de Gálibos de MDF 
La capacitación de técnicos y operarios es una valiosa oportunidad de mantener estos oficios tradicionales y puede ser una fortaleza en la que se apoye un relanzamiento de las actividades industriales, que hoy dan servicio a embarcaciones del clúster náutico del Área Metropolitana de Buenos Aires.

En cuanto a la navegación, el sistema portuario de Nueva Palmira es el principal del área, segundo en importancia del Uruguay, después del puerto de Montevideo. La ciudad debe su nombre a su fundación en el cruce de rutas comerciales, al igual que la histórica Palmira de Siria. Su ubicación privilegiada en un punto de la costa del río Uruguay que permite el arribo de buques transoceánicos, le confieren un rol estratégico como puerta de la Hidrovía, y por él sale al océano la producción de un vasto hinterland de escala continental. La ciudad también cuenta con un puerto deportivo de la DNH, la Dársena Higueritas.

Además de las instalaciones portuarias de Nueva Palmira, del arroyo de Las Vacas, de la dársena Higueritas, y del puerto Conchillas, en el área hay otros muelles y embarcaderos, de los cuales los más relevantes son la marina Las Víboras, de uso privado, y el puerto San Juan, vedado a la navegación desde 2005 por asuntos de seguridad de la residencia presidencial de Anchorena. En la actualidad, se está construyendo en Punta Pereira, contigua a Conchillas, una zona franca y puerto originalmente proyectados para la fábrica de pulpa de celulosa de capitales españoles ENCE, emprendimiento adquirido en 2009 por Arauco-Stora Enso.

4.2 La navegación, los astilleros y el estado del ambiente: presiones, impactos y respuestas

Como toda actividad humana, la navegación, la construcción naval y las actividades de los astilleros presionan sobre el ambiente, generando impactos de diferente importancia. La evaluación del estado del ambiente en relación a

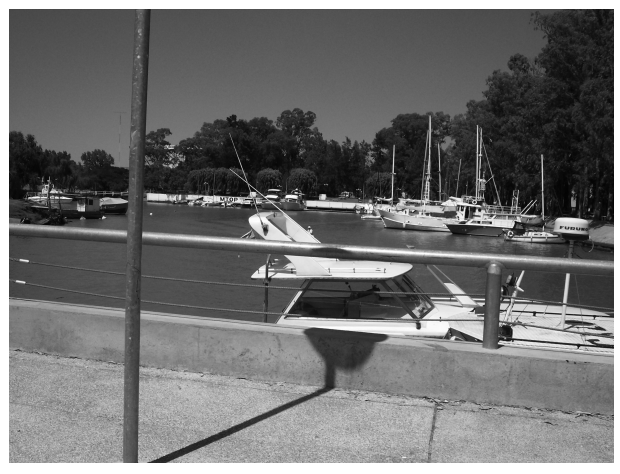

Dársena Higueritas, Nueva Palmira

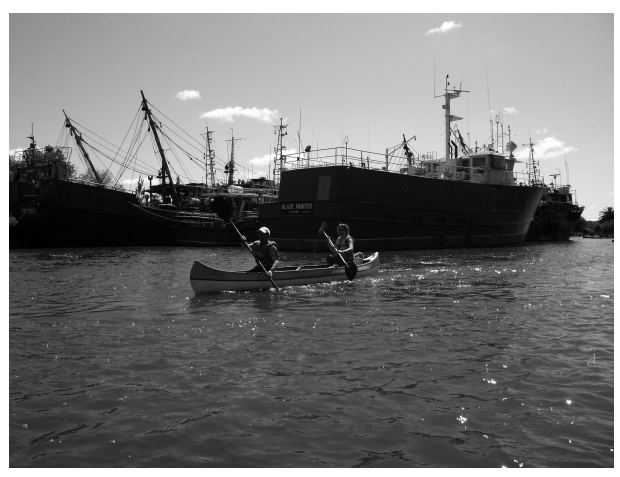

Embarcaciones en desuso en Astillero Maffoni, en el arroyo de las Vacas 
estas actividades permitirá realizar una valoración de beneficios, activos y pasivos ambientales, que habilitará la toma de decisiones para un adecuado manejo de los recursos costeros. Para realizar esta evaluación el enfoque más adecuado es el Manejo Costero Integrado ( $\mathrm{MCl}$ ), que prevé la participación de actores que toman diferentes roles en la sociedad: técnicos, emprendatarios, tomadores de decisión y las comunidades que comparten los recursos costeros. Este proceso conducirá a una jerarquización de las percepciones de los problemas que esté directamente vinculada a los intereses, las capacidades y las prioridades de la comunidad. La evaluación del estado del ambiente debe pasar, por lo tanto por un proceso participativo.

A la identificación local de la navegación comercial, se suma la importancia de los astilleros, y las razones por las que se establecieron en Carmelo, desde las razones relacionadas con la ubicación estratégica hasta las razones de tipo cultural.

La pesca artesanal a su vez tiene el carácter emblemático de actividad local y de conocimiento del río.

Las diferentes escalas de navegación conforman una actividad mancomunada, que es parte de una cultura que va de lo local a lo internacional, de la chalana de pesca fluvial al transatlántico interoceánico. Cada uno es un elemento individual, pero a su vez se puede transformar en el paisaje donde confluyen esas imágenes, que se concretan en el mismo espacio, y, en ocasiones, en el mismo tiempo: un barco cerealero cargando, un velero en la misma dársena, barcas de pesca en el muelle costero más allá. Todos trabajando de forma independiente en su actividad, y mancomunada en el paisaje, aún cuando introducimos la dimensión temporal.

Estos paisajes generan potentes impactos visuales, que en un contexto de gestión ambiental adecuada pueden ser incorporados a las imágenes emblemáticas del lugar y convertirse en temas icónicos para el posicionamiento

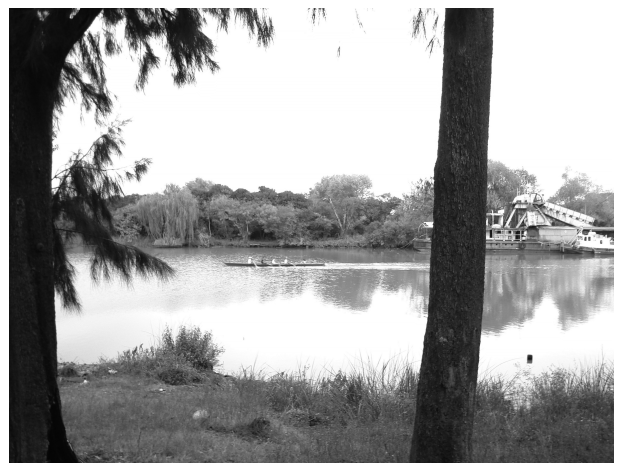

Remo en Carmelo, sitio de entrenamiento de los representantes uruguayos a los Juegos Olímpicos de Pekin 2008

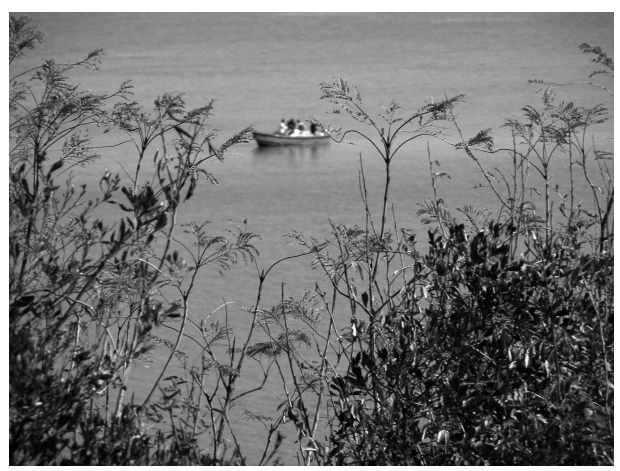

Pesca artesanal en Punta Gorda 
ID_INVESTIGACIONES

del área. La temática portuaria y de astilleros puede explotarse desde el punto de vista estético incluso a nivel de las artes plásticas, como lo demuestra la obra del artista nacional Joaquín Torres García, o del artista local Rogelio Ferrari.

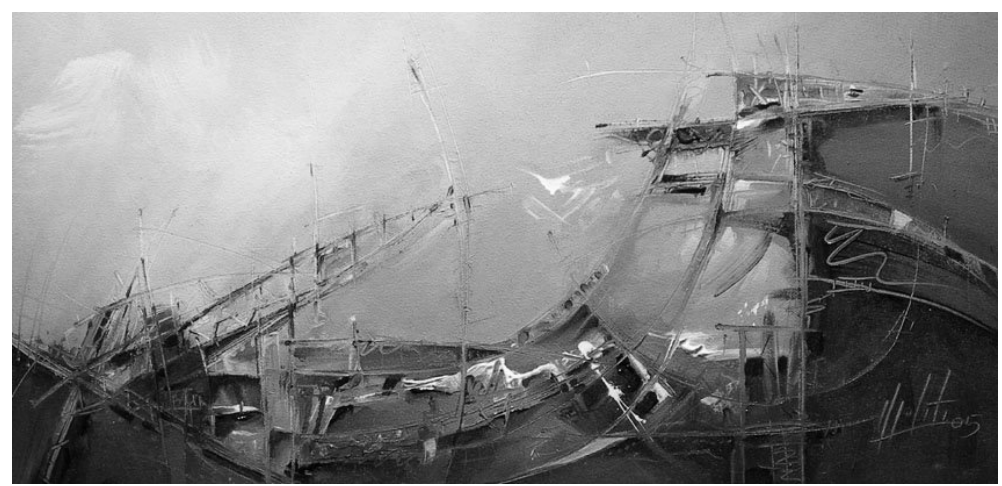

Puerto. Acrílico sobre lienzo, 2005. Cortesía del autor: Ippoliti.

\subsection{La explotación y el comercio de áridos y materiales de construcción}

Por sus huellas en el espacio costero, y la importancia que tuvo para el desarrollo de la navegación y de los astilleros, esta actividad es parte del eje temático.

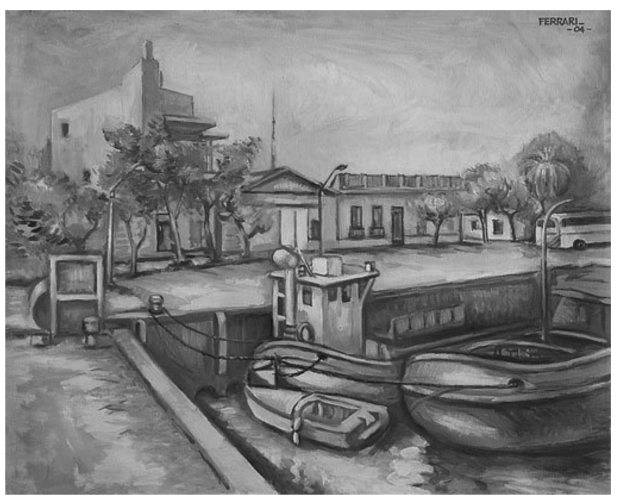

El embarcadero Las Vacas, Carmelo 2004. Rogelio Ferrari

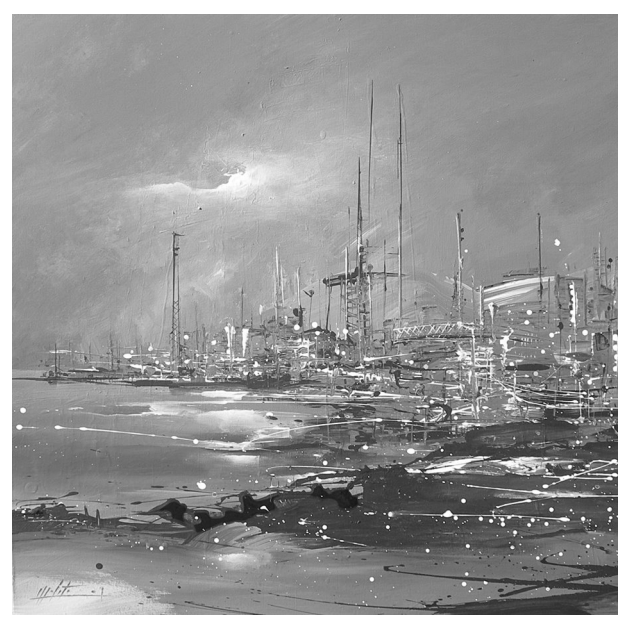

Portuaria. Acrílico sobre lienzo, 2009. Cortesía del autor: Ippoliti 


\section{ID_INVESTIGACIONES}

Dada la gran disponibilidad en estas costas, la arena, la piedra y la cal se exportaron desde épocas fundacionales para la construcción de edificios e infraestructuras de Buenos Aires, cuyo sustrato no presenta la misma geología. La actividad extractiva está presente en la costa, en las infraestructuras en fase de abandono, y en la toponimia. La fotografía satelital permite visualizar huellas y vestigios de esta actividad sobre la costa coloniense: antiguas canteras convertidas en espejos de agua, campos de dunas horadados, un importante número de infraestructuras costeras e instalaciones mineras en fase de abandono, déficit de arena evidente en algunos sectores de la costa, y paisajes fuertemente modificados por el hombre, que asilvestrados, se han estabilizado en nuevos equilibrios con alta biodiversidad y características de interesante paisaje cultural.

Desde 1978 en adelante, diversos instrumentos jurídicos han prohibido esta actividad en la zona costera para detener el deterioro. No obstante en Colonia como en todos los departamentos costeros, existen importantes industrias extractivas autorizadas fuera de la Faja de Defensa de Costas. Un comentario especial merece la actividad desarrollada por los jesuitas en la estancia "del Río de las Vacas" (hoy denominada "Calera de las Huérfanas"), dependiente del Hospicio y Colegio bonaerense de "Nuestra Señora de Belén", fundada en 1741 (Geymonat, 2010). Este establecimiento fue administrado más tarde por Juan de San Martín, padre del prócer argentino José de San Martín, cuya familia residió entonces en el establecimiento. Los hornos de cal de la Calera de las Huérfanas abastecieron por largos años a la industria de la construcción de la ciudad de Buenos Aires. En la actualidad, este establecimiento declarado Monumento Histórico Nacional está siendo objeto de planes de conservación y gestión.

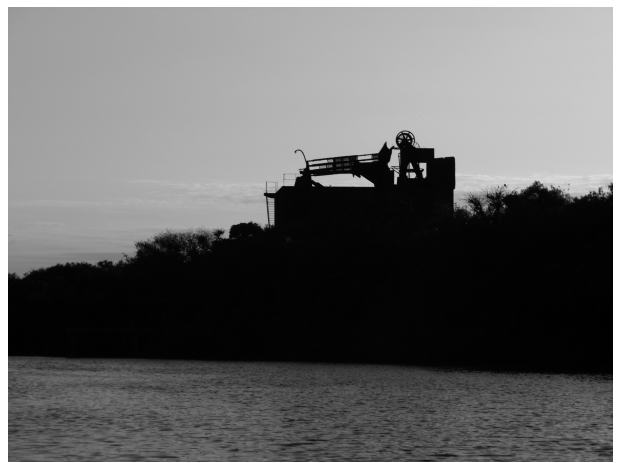

Ruinas jesuíticas de la Capilla de las Huérfanas

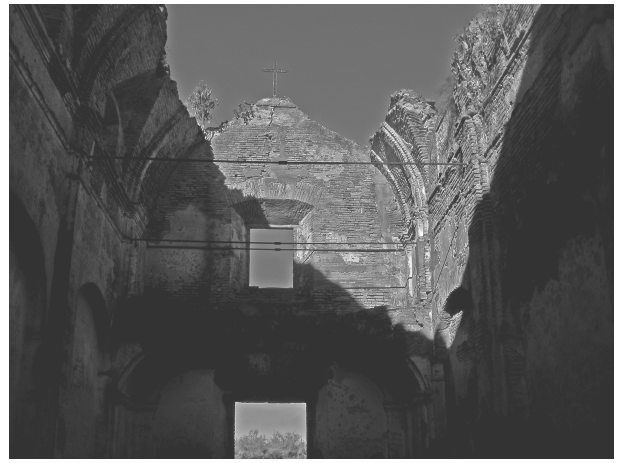

Horno de cal en Calera de las Huérfanas 


\section{ESTRUCTURACIÓN DE UN EJE TEMÁTICO ESPECÍFICO: UN ALICIENTE PARA LA RECUPERACIÓN DE AMBIENTES Y EL DESARROLLO SOSTENIBLE}

La vitalidad de la navegación deportiva y recreativa, la importancia económica de la navegación comercial, el valor social y cultural de la pesca artesanal, su presencia en el paisaje y sus implicaciones ambientales sobre la biodiversidad, el valor patrimonial de los oficios tradicionales y su significación a nivel de la comunidad y su identidad, son características que pueden potenciar la implementación de una línea de trabajo o eje temático que aporte al desarrollo sostenible. La adecuada gestión de las actividades económicas y la preservación del medio ambiente habilitarían la puesta en valor del patrimonio natural y cultural, y fortalecería la gestión de las infraestructuras costeras recreativas y de defensa de costas.

Sería posible implementar diversas actividades turísticas y productivas relacionadas con recorridos en embarcaciones para la observación de los paisajes naturales de la costa, y de los paisajes culturales que constituyen estos sitios. A la vez, permitiría poner en valor sectores del tejido urbano, y elementos singulares como áreas naturales urbanas, o antiguas construcciones de casas del siglo XIX y principios del XX, que otrora fueron una expresión de la pujanza local, y que hoy se "empastan" en áreas no calificadas, sin servicios ni equipamientos públicos.

Para involucrar los predios donde hay o ha habido astilleros o varaderos, se debería promover el desarrollo sostenible de la actividad, capacitando e incentivando a los emprendimientos activos a la adopción de prácticas de producción más limpia $(\mathrm{P}+\mathrm{L})$, y a las autoridades locales a implementar medidas directas de limpieza y restauración ambiental en predios abandonados o costas silvestres del arroyo, para mejorar el estado del medio ambiente a partir de una actividad que generaría ingresos en forma directa, y de forma

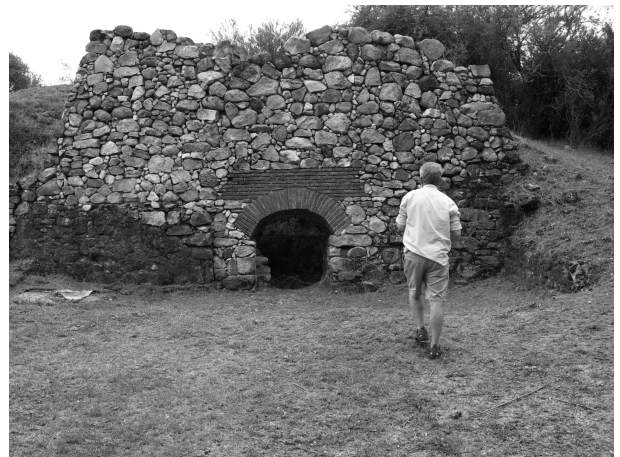

Ruinas jesuíticas de la Capilla de las Huérfanas 


\section{ID_INVESTIGACIONES}

indirecta al agregar atractivos turísticos a la propuesta local. Permitiría además abrir la ciudad hacia sectores donde la costa del arroyo es una suerte de borde trasero olvidado del tejido urbano. De este modo, podría valorizarse el suelo urbano en áreas ya antropizadas, incorporando al mercado inmobiliario áreas reposicionadas. Al hacerlo, se podría quitar presión sobre sectores costeros más frágiles como lo son la costa sobre el Río de la Plata, sometida a una fuerte presión inmobiliaria, a la vez que está expuesta a presiones originadas en el cambio climático y la variabilidad, con el aumento del nivel medio del mar asociado, su mayor frecuencia de eventos climáticos extremos, inundaciones y tormentas.

Por último, la puesta en valor de las antiguas canteras y de sus infraestructuras para la navegación, podría dar oportunidad a pequeñas iniciativas locales: senderismo, buceo, e incorporación a circuitos históricos.

\subsection{El marco jurídico}

El marco jurídico para la implementación de un parque de este tipo comprende varios instrumentos con distinta jerarquía e importancia. Desde la Ley de Centros Poblados de 1946 hasta nuestros días, Uruguay ha ido incorporando paulatinamente diversos instrumentos que permiten generar figuras de ordenamiento territorial desde enfoques multi e interdisciplinarios, a las diferentes escalas de gobierno. Esto se ve plasmado en la Ley de Ordenamiento Territorial y Desarrollo Sostenible (LOTYDS) de 2008, donde se prevé el desarrollo de instrumentos de acción concertada e integrada, y otras modalidades que incluyen diversos instrumentos económicos y financieros. Son relevantes también las normas relativas a la protección del medio ambiente, desde el marco jurídico nacional, hasta los convenios y tratados internacionales suscritos por Uruguay. La implementación de instrumentos de protección transfronterizos requiere además de las decisiones técnicas y políticas, un fuerte análisis de estos últimos. Una propuesta de área protegida binacional fue 


\section{ID_INVESTIGACIONES}

presentada por Brazeiro et al. (2007), para el Islote Timoteo Domínguez, que en la actualidad está unido a la Isla Martín García (República Argentina) convirtiéndose en el único límite terrestre entre ambos países.

Tanto la delimitación geográfica, como el grado de protección ecosistémica y patrimonial del parque, deben regirse por la legislación nacional, y apoyarse en ella. En particular, el asunto de clave puertos y vías navegables, podría utilizar la figura "área de recursos manejados" para implementar la protección de algunos sectores de la cuenca del arroyo de las Vacas y del río San Juan. En la dimensión acuática las actividades están reglamentadas por un marco jurídico específico, dedicado a las obras de infraestructura y a la navegación propiamente dicha.

El marco jurídico vigente no incorpora propuestas de instrumentos económicos $y$ financieros para incentivar el desarrollo de una propuesta de la naturaleza de un parque.

\subsection{La gestión: instrumentos, procesos locales, factibilidad y liderazgo}

La LOTYDS antes citada ha fortalecido a los gobiernos departamentales y municipios en la administración de su espacio territorial, promoviendo la necesidad de que los gobiernos departamentales, ya desde una óptica individual o en asociaciones con sus iguales, generen Instrumentos de ordenamiento territorial a partir de planes locales. Estos instrumentos si bien deben estar aprobados por el gobierno central, deben tener una etapa consultiva con la población local, involucrada a los efectos de obtener un plan local consensuado con la sociedad civil y todos los sectores del estado que deben ser consultados. Es responsabilidad del gobierno departamental y del/los municipio/s su implementación y gestión. El parque puede ser una parte o el todo de un Plan Local, y debería tener un Plan de Manejo propio donde se 


\section{ID_INVESTIGACIONES}

explicitaran sus objetivos, la modalidad de gestión, una propuesta de financiación y un mecanismo para la coparticipación de todos los actores involucrados.

La implementación de una propuesta de parque requerirá elaborar una estrategia que estructure las acciones, acordada entre los actores, de tal manera de desencadenar procesos que permitan su apropiación por parte de los involucrados. Es deseable que la propuesta surja a través de un consenso de los gobiernos locales y de los actores de la sociedad civil involucrados. EI plan de manejo específico debe surgir en el ámbito de la coparticipación y los compromisos asumidos, en función de una opción por los beneficios y las oportunidades.

La materialización de un plan de manejo consensuado podría tener el formato de un "Convenio Socio-gubernamental" de coparticipación en la valorización microrregional, ejecutado a través de un equipo interdisciplinar, que impulse y controle las acciones y los acuerdos elaborados. Este convenio fijará los grandes objetivos hacia los cuales apuntará el parque, y las políticas a ser llevadas adelante en períodos claramente establecidos. Las medidas a implementar deberán monitorearse, actualizarse y sustituirse con el transcurso del tiempo, en un proceso de mejora continua. Transcurridos los plazos de vigencia del mismo, y a la luz de las evaluaciones y mediciones realizadas, se realizarán nuevos procesos de discusión, y se renovará el compromiso colectivo, buscando una adhesión cada vez mayor por parte de los pobladores, ampliando los consensos detrás de los objetivos, e implementando los instrumentos económicos y financieros que permitan su sustento y desarrollo.

El Parque funcionará como un emprendimiento bajo la forma administrativa más conveniente, sea pública, privada o mixta, e integrará los diferentes actores: los gobiernos departamentales o locales, las instituciones públicas, los 
ID_INVESTIGACIONES

actores del mercado y los miembros de la sociedad civil interesados en la coparticipación.

Si bien a nivel nacional existen múltiples organismos con competencia ambiental y costera, representantes de cada uno de los ministerios nacionales, el universo participativo local muestra que el gobierno nacional toma un rol periférico, y el mayor peso relativo lo tiene la junta local.

\section{Organigrama General de las Instituciones con competencia ambiental y costera}

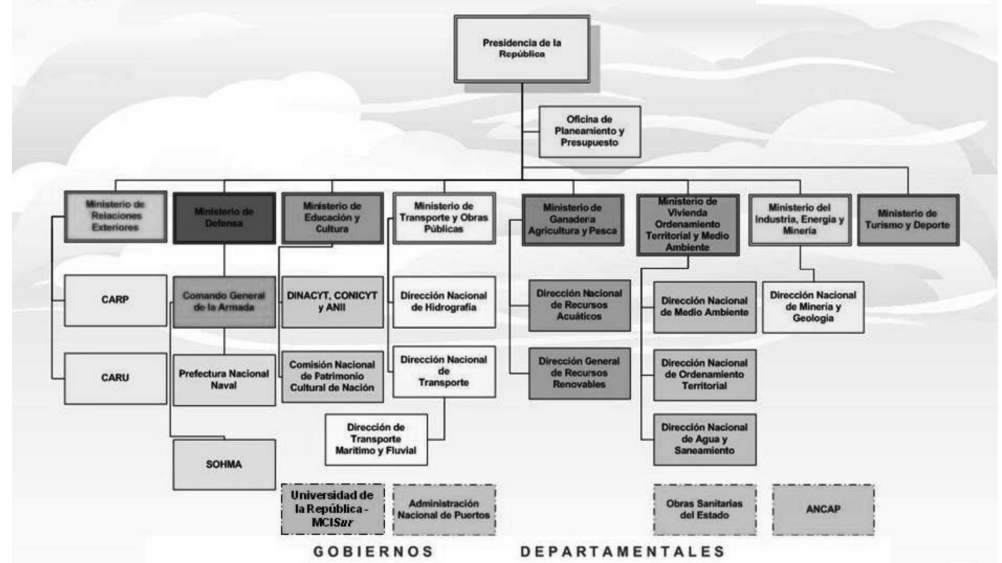

Instituciones con competencia ambiental y costera para el Caso de Estudio CarmeloNueva Palmira. Fuente: Perdomo et al., 2008

Perdomo et al. (2008) identifican cierta falta de asociaciones civiles organizadas con capacidad de liderazgo y de implementación de propuestas de gestión de este tipo. Esto es consistente con el diagnóstico realizado con el GEO-Colonia del Sacramento (PNUMA, 2009). En actividades de diagnóstico local realizado por PNUMA en la elaboración del informe GEO-Carmelo, así 
ID_INVESTIGACIONES

como en otros foros de búsqueda de consensos sociales realizados en el área, nuevamente se percibe la necesidad del fortalecimiento de la generación de una cultura de participación pública en pro de la valorización de los espacios de la sociedad allí residente.

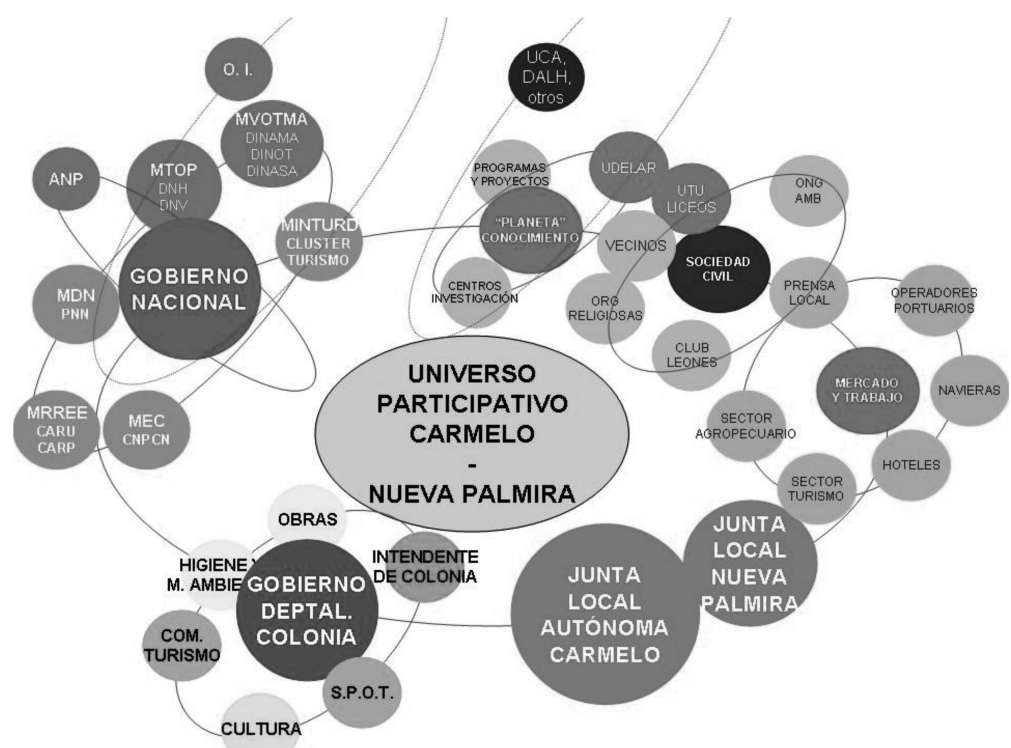

Universo participativo de Carmelo y Nueva Palmira. Fuente: Perdomo y Olveyra. Modificado de Barragán 2005

\section{CONCLUSIONES}

La estrategia de $\mathrm{MCl}$ propuesta en torno a los asuntos clave identificados es prioritaria para el desarrollo sostenible en el área de Carmelo y Nueva Palmira. Un parque patrimonial implementado en base a la activación del patrimonio natural y cultural es una figura aplicable, y permitiría articular la participación y 


\section{ID INVESTIGACIONES}

el compromiso de los actores locales con la actividad turística para potenciar los atractivos del área, contribuyendo al desarrollo sostenible.

El relato "Navegación y Astilleros Orientales" tiene alto potencial como eje temático para la implementación del parque.

\section{BIBLIOGRAFÍA}

BACIGALUPE, Juan Francisco (2009). Astillero Carmelo de MDF S.A. En Historia y Arqueología Marítima. http://www.histarmar.com.ar/InfHistorica-2/AstCarmeloNDF-1.htm. Diciembre 2009

BLASINA, Eduardo (2009). Darwin en el Plata. El Descubrimiento de la Evolución. Ediciones de la Banda Oriental. ISBN 978-9974-1-0623-9. Montevideo, 2009.

BRAZEIRO, Alejandro, Marcelo ACHA, Hermes MIANZAN, Mónica GÓMEZ, Virginia FERNÁNDEZ \& Alejandra VOLPEDO (2007). Propuesta de Sistema Binacional de Áreas Marinas Protegidas en el Río de la Plata y su Frente Marítimo. II Congreso Latinoamericano de Parques Nacionales y otras Áreas Protegidas - 2007. Bariloche. Argentina.

BRAZEIRO, Alejandro, \& Omar DEFEO (2006). "Bases ecológicas y metodológicas para el diseño de un Sistema Nacional de Áreas Marinas Protegidas en Uruguay". En R Menafra, L Rodríguez-Gallego, F Scarabino y D Conde (Eds.). Bases para la conservación y el manejo de la costa uruguaya" VIDA SILVESTRE URUGUAY, Montevideo, 2006. i-xiv + $668 p p$

CAYSSIALS, Ricardo; HERNÁNDEZ, Juan; CANTÓN, Victor; FERNÁNDEZ, Virginia; LÓPEZ, Jorge y COLLAZO, Daniel (1999). "Caracterización del Medio Físico". En Diagnóstico Ambiental y Sociodemográfico de la Zona Costera Uruguaya del Río de la Plata. EcoPlata. 1999 


\section{ID_INVESTIGACIONES}

GEYMONAT, Jacqueline y Anahí LAROCA. La Calera de las Huérfanas hoy. Hacia una valorización sostenible del Patrimonio Cultural. Disponible en http://www.ceibal.edu.uy/contenidos/areas_conocimiento/cs_sociales/081018calera/.

Consultado en mayo 2010

Instituto del Tercer Mundo (2008). Guía del Mundo. Montevideo, 2008.

KRAVETS Iryna y DE CAMARGO, Patricia (2008). "La importancia del turismo cultural en la construcción de la identidad nacional". En CULTUR, Revista de Cultura e Turismo. CULTUR, Año 2. No 2. Julio 2008. Disponible en http://www.uesc.br/revistas/culturaeturismo. Consultado en mayo 2010.

LANZILOTTA Bibiana, ROCHE, Hugo (2003). Intercambio Comercial y Transporte Marítimo Fluvial en la Cuenca del Plata. FREPLATA. 2003

LÓPEZ, Jorge (1997). "Marco Geomorfológico y Geológico del Río de la Plata”. En El Río de la Plata. Una revisión ambiental. Un Informe de Antecedentes del Proyecto EcoPlata. Cap. 1. Julio de 1997.

LOUREIRO, Marcelo \& Rafael O. DE SÁ (2006) Osteological analysis of the killifish genus Cynolebias (Cyprinodontiformes: Rivulidae). Department of Biology, University of Richmond, Richmond, Virginia. 2006

MÉNDEZ, Rosa (2008). De la invención de las raíces a los procesos de la patrimonialización folklórica. http://usuarios.lycos.es/odiseomalga/pc03.htm. 17.03.2008.

OLVEYRA, Gustavo y Raquel IPPOLITI (2009). Parque Natural Regional del Litoral Oriental. Maestría en Ordenamiento Territorial. Instituto de Teoría y Urbanismo. Facultad de Arquitectura. Inédito, disponible en https://sites.google.com/site/litoraldecarmelouruguay/.

PARODI, Luis Gonzalo. Historia. Material cedido a CiudadCarmelo.com, sitio web de la ciudad de Carmelo, disponible en http://www.ciudadcarmelo.com/historia.htm. Consultado en mayo 2010.

PAYS DU COTENTIN. Charte de développement durable 2002. Disponible en http://www.paysducotentin.fr/iso_album/charte_du_pays_du_cotentin_24042003.pdf 


\section{ID INVESTIGAC IONES}

PERDOMO, Ana; COLLAZO, Daniel; OLVEYRA, Gustavo; IPPOLITI, Raquel (2008). Caso de Estudio Carmelo - Nueva Palmira. Maestría en Manejo Costero Integrado MCISur. Universidad de la República - Uruguay | Dalhousie University - Canadá. Inédito. Disponible en http://sites.google.com/site/casocolonia/

PERDOMO, Ana; COLLAZO, Daniel; OLVEYRA, Gustavo; IPPOLITI, Raquel (2009). Caminos hacia el manejo costero integrado. Carmelo - Nueva Palmira. EcoPlata - MCISur UDELAR-Dalhousie. Montevideo, 2009.2 Disponible en http://sites.google.com/site/casocolonia/

PERDOMO, Ana y OLVEYRA, Gustavo (2009). Evaluación Carmelo Nueva Palmira. Curso Gestión Integrada de Áreas Litorales. Profesores Dr. Adolfo Chica Ruiz y MSc Marisa Pérez Cayeiro. Grupo PGIAL Universidad de Cádiz - EcoPlata. Inédito, disponible en https://sites.google.com/site/litoraldecarmelouruguay/.

PEREYRA, Fernando X. (2004). "Geología urbana del área metropolitana bonaerense y su influencia en la problemática ambiental”. En Revista de la Asociación Geológica Argentina. Versión impresa ISSN 0004-4822. Rev. Asoc. Geol. Argent. v.59 n.3 Buenos Aires jul/sep 2004.

PRATS; Llorenç (1997). Antropología y Patrimonio. Ariel Antropología. Barcelona, 1997.

REBORATTI, Carlos. Población. AABA - Atlas Ambiental de la Provincia de Buenos Aires. Agencia de Promoción Científica y Tecnológica (SECYT), Gobierno de la Ciudad Autónoma de Buenos Aires (GCABA), CIGA-MACN (CONICET), FADU-UBA. Disponible en http://www.atlasdebuenosaires.gob.ar. Consultado en mayo 2010.

SABATÉ, Joaquín (2004). "Paisajes culturales. El patrimonio como recurso básico para un nuevo modelo de desarrollo". Madrid, $2004 . \quad$ En http://www.eukn.org/espana/themes/Urban_Policy/Urban_environment/Cultural_heritage /paisajes_culturales_1111.html

SARUBBI Alejo, PITTAU, Marcos y MENÉNDEZ, Ángel (2005). Delta del Paraná: Análisis Cartográfico. Proyecto "Simulación y Predicción del Crecimiento del Frente del Delta del Río Paraná" Proyecto PICT 9351 BID 1201/OC-AR. Ezeiza, 2005. 
ID_I N VESTIG ACIONES

SORIANO, Mireya (1995). Administración Nacional de Puertos. Coastal Erosion in Colonia, Uruguay. International Conference on Coastal and Port Engineering in Developing Countries, Brasil, 25/29 setiembre 1995.

Otra bibliografía consultada

Ministerio de Bienes Nacionales. Gobierno de Chile. Rutas Patrimoniales. Desierto de Atacama Ex Oficina salitrera Chacabuco.

Observatori del Paisatge de Catalunya. Prototipus de catàleg de paisatge. Document de referència per alls grups de treball. Olot y Barcelona, mayo de 2006.

Observatori del Paisatge de Catalunya. Prototipo de Catálogo de Paisaje. Resumen del documento de referencia para los grupos de trabajo (edición revisada) Olot y Barcelona, mayo de 2006.

PACC - PRC. Turismo en Colonia. Plan de Refuerzo de la Competitividad. "Programa de Competitividad de conglomerados y cadenas productivas". MINTURD, IMC, OPP, DIPRODE: PACC. Julio 2007.

Provincia di Bologna. Piano territoriale di coordinamento provinciale. Accesible en: http://cst.provincia.bologna.it/ptcp

Universidad de Gerona. Participación ciudadana en los catálogos de paisaje. Observatorio del Paisaje, accesible en: www.catpaisatge.net

Entrevistas:

Bacigalupe Juan Francisco. Técnico en Construcciones Navales. Ex alumno de ERCNA Carmelo, historiador. 27 julio de 2010.

Merillo, Rodolfo. Director de ERCNA. Técnico en Construcciones Navales. Ex alumno de ERCNA. 19 agosto 2010. 